\title{
SALUD
}

\section{Perfil del profesional de Enfermería en Paraguay. Año 2017}

\author{
Zunilda Garay Duarte ${ }^{1}$
}

\section{Resumen}

Introducción: El perfil de egreso es el conjunto de cualidades y características que de acuerdo a los conocimientos, habilidades, aptitudes y valores le permiten a una persona asumir las actitudes y competencias requeridas en una responsabilidad definida también, como la imagen contextualizada de la profesión en un momento y lugar, que orienta la determinación de los objetivos curriculares, sirve de referencia para la valoración de la calidad de la formación. En la República del Paraguay, el/la Enfermero/a es un/a profesional universitario/a generalista con competencias científico - técnicas, humanística, ética, legal, social y política; comprometido con la calidad de vida de las personas, en todo su ciclo vital, familiar y comunitario en sus diferentes contextos; con actitud crítica y reflexiva. Trabaja en la promoción de la salud, prevención de las enfermedades, curación y rehabilitación y en la etapa final de la vida, en todos los niveles de complejidad y/o en forma independiente. Provee cuidados autónomos e interdependiente, supervisa, administra, investiga y educa en diferentes áreas, e instruye al personal de enfermería y de atención de la salud, capacitado para gestionar su desarrollo profesional, con la finalidad de contribuir en la construcción de una sociedad más equitativa, justa y solidaria. El perfil de egreso de la carrera, en lo esencial, destaca el conjunto de capacidades, habilidades y actitudes que debe adquirir el egresado. Constituye un referente esencial para el diseño y la revisión curricular para la gestión docente, así como para la evaluación y acreditación de la carrera. El/la egresado/a de Enfermería es la persona que ha adquirido competencias científicas y técnicas, humanística, ética, legal con actitud crítica reflexiva, social y política para dar atención integral al individuo, familia y comunidad a través del ejercicio general profesional fundadas en las ciencias biológicas, de la conducta y de enfermería. Ejerce su rol con liderazgo, administra, investiga y educa en diferentes áreas a fin de lograr mayor equidad, solidaridad y desarrollo humano y participa como miembro activo de organizaciones profesionales de enfermería. Actualmente se requiere profesionales en Enfermería cuyo perfil de egreso pueda responder a los cambios que ha traído consigo la globalización. Este énfasis en la necesidad social del desarrollo de Pensamiento Crítico ha sido expresado por la Conferencia Mundial sobre la Educación Superior (UNESCO,

1. Instituto Andrés Barbero, Filial Quindy, Universidad Nacional de Asunción, Paraguay.

E-mail: zunichamorro82@hotmail.com

DOI: $10.26885 /$ rcei.foro.2017.143 
1998) y ratificado en diversas oportunidades, como en el año 2009 (UNESCO, 2009), en el que además se vinculó a la investigación como elemento clave para la formación universitaria, que debe alinear los currículos con las demandas sociales, incluyendo por tanto la formación de aspectos que van más allá de la formación tradicional centrada en la adquisición de conocimientos. La formación de los profesionales de enfermería se desarrolla en paralelo con la de disciplina científica, como profesión transdisciplinaria del campo de las ciencias sociales y de la salud, en la cual va clarificando su objeto de estudio e intervención como el "cuidado humano", asociado al desarrollo, la protección y recuperación de la salud, lo que beneficia al "sujeto humano como ser cultural, a la familia, a los grupos, a las comunidades y a la sociedad como unidades de análisis y cuidado. El objetivo de la investigación es determinar el perfil del titulado de Licenciatura en Enfermería en Paraguay.

Materiales y Método: Se trata de una revisión bibliográfica sobre el perfil del Licenciado en Enfermería, cuyos datos se obtuvieron de las páginas web de las propias universidades, utilizando como criterios de selección: universidades que formaran licenciados en Enfermería, universidades públicas y privadas en el año 2017. Se incluyeron 16 instituciones formadoras. Esta investigación consideró dentro de sus aspectos la integridad de la información y los principios bioéticos de beneficencia y no maleficencia.

Resultados: Los componentes del perfil definidos, constituyen requisitos básicos de los egresados se encontraron en el 100\% la formación humanística, ética, social, política y calidad humana, formación científica y técnica y los niveles de atención (prevención, promoción, recuperación y rehabilitación), $94 \%$ con competencia en planificación, ejecución y evaluación del cuidado $88 \%$ servicio integral, $81 \%$ competencia en educación, liderazgo y toma de decisiones, $68 \%$ competencia en gestión y formación en investigación, 38\% actitud crítica y reflexiva, el $25 \%$ conocimiento cultural y el $6 \%$ compromiso con el medio ambiente.

Conclusión: El perfil del licenciado en Enfermería es diferente entre las instituciones formadoras en el país, es necesario orientar los programas de formación de futuros profesionales, sus perfiles y áreas de desempeño, acordes con los actuales escenarios y contextos, enmarcados en un mundo globalizado y cambiante, reconociendo y valorando la cultura y fomentando el pensamiento crítico.

Palabras clave: perfil, egreso, enfermería.

\section{Referencias}

Luengo Martínez, C. E. \& Sanhueza Alvarado, O. (2016). Formación del licenciado en Enfermería en América Latina. Aquichan., 16(2), 240-255. doi: 10.5294/ aqui.2016.16.2.11

OPS/OMS. (2007). Orientaciones para la Educación Inicial de Enfermería en las Américas: hacia el 2020. Recuperado de http://www.eean.ufrj.br/aladefe/ 
orientaciones.pdf

Torres, J. \& Urbina, O. (2006). Perfiles profesionales, funciones y competencias del personal de Enfermería en Cuba. Educ Med Sup., 20(1). Recuperado de http://www.bvs.sld.cu/revistas/ems/vol20_1_06/ems02106.htm

Universidad Nacional de Asunción. Instituto Dr. Andrés. Barbero. (2014). Recuperado de http://www.iab.una.py/index.php/academico/carreras/ licenciatura-en-enfermeria 